\title{
The partial reinforcement effect and the subjective value of collectibles
}

\author{
MELVIN L. GOLDSTEIN \\ Indiana University, Kokomo, Indiana 46901
}

\begin{abstract}
The paper describes the application of the partial reinforcement effect to the acquisition of value by collectibles such as stamps, coins, and antiques. These items acquire value by long exposure to the marketplace. The subject may follow the price of these items, and, as he sees them go up in price, he may expect them to go up indefinitely, but they do not. They go up in price in small steps and he is reinforced every time they go up. He, therefore, becomes emotionally attached to them and cannot let go in time to get out of the situation when the prices collapse. The solution to this problem is to sell the item in question when it reapproaches the original value and never to expect to reach the peak value from which it plunged.
\end{abstract}

According to the partial reinforcement effect, animal behavior should be sustained at a greater level of performance with partial reinforcement than with continuous reinforcement. The idea, here, is that when the animal gets a small reward for a performance, he learns to "expect" a larger reward, and this keeps him going, so that a series of small rewards would be more effective than one large reward.

How is this principle applied to human gambling behavior? In a lottery situation, when a person wins a small reward, he starts to expect a larger reward and this keeps him spending his money on the large reward.

How do things acquire value? Let us say that a person follows stock " $\mathrm{X}$ " on the stock exchange and it goes up in small steps; he then expects it to continue up indefinitely, and he is often surprised when it does not.

The same effect probably occurs in collecting antiques. coins, stamps, and other items that have no intrinsic value of their own but acquire value through long exposure to the marketplace.

The subject may follow the price of these items and, as he sees them go up in price, he may expect them to go up indefinitely, but they do not. They go up in price in small steps, and he is reinforced every time they go up.
$\mathrm{He}$, therefore, becomes emotionally attached to them and cannot let go in time to get out of the situation when the prices collapse.

This has happened, repeatedly, in the past. One good example is the recent upsurge in the price of gold and other precious metals. When the price of gold went from $\$ 400 /$ oz to over $\$ 800 /$ oz last year, many people held on and did not sell, thinking the price would reach $\$ 1,500 / \mathrm{oz}$. This also happened several years back when there was a speculative surge in Ryukyus Island stamps and more recently, in stamps of Great Britain ("The Seahorses") and the U.S. Zeppelin stamps. This happened, also, last year when rare U.S. type coins had a strong upsurge, which did not last.

When such an effect occurs, the typical reaction is to believe that the price of the item in question will eventually get back to where it was, so the subject keeps holding on, but such a return rarely happens.

The solution to this problem is to sell the item in question when it reapproaches the original value and never to expect it to reach the peak value from which it plunged.

(Received for publication June 9, 1981.) 